www.nature.com/ejhg

\title{
RNA-based mutation screening in German families with Sjögren-Larsson syndrome
}

\author{
C Kraus, C Braun-Quentin, WG Ballhausen and RA Pfeiffer \\ Institut für Humangenetik, Universität Erlangen-Nürnberg, Germany
}

\begin{abstract}
Sjögren-Larsson syndrome (SLS) is a rare autosomal recessively inherited disorder characterised by mental retardation, spasticity and ichthyosis. SLS patients have a profound deficiency in fatty aldehyde dehydrogenase (FALDH) activity. The human CDNA of FALDH has been shown to map to the SLS locus on chromosome 17p11.2. Here we describe a method based on reverse transcriptase-polymerase chain reaction (RT-PCR) and protein truncation test to identify mutations in the FALDH gene in nine German SLS families. Using this detection system both disease-causing mutations were found in eight of the nine SLS families examined (17/ 18 chromosomes). Seven different mutations were identified: an exon 2 skipping due to exon 2 splice donor mutation; two different exon 3 splice donor mutations resulting in combined exon 2 and 3 skipping; a 906delT deletion in exon 6; a genomic deletion of about 6 kb including exon 9; a 1277T > G transversion resulting in a Leu426Ter nonsense mutation; and a 1297delGA deletion. Two of the mutations identified, the genomic exon 9 deletion and the 906delT in exon 6 affected five out of seven SLS patients from a small region of Northern Bavaria. Therefore these two mutations accounted for $71 \%$ (10/14 chromosomes) of Bavarian SLS alleles and so far have not been described in SLS families from other countries. Our findings do not support our 'historical' hypothesis, that a possible region clustering in Northern Bavaria could be due to the presence of Swedish soldiers during the 30 Years War (1618-1648), but suggest that two mutations causing SLS syndrome originated in Northern Bavaria. European Journal of Human Genetics (2000) 8, 299-306.
\end{abstract}

Keywords: Sjögren-Larsson syndrome; fatty-aldehyde dehydrogenase (FALDH) gene; mutation screening; reverse-transcriptase polymerase chain reaction; protein truncation test; mRNA decay

\section{Introduction}

Sjögren-Larsson syndrome (SLS) is an autosomal recessive disorder which is characterised by the presence of ichthyosis, slowly progressive spastic diplegia or tetraplegia, and mental retardation. ${ }^{1-3}$ The ichthyosis is usually congenital and first brings the patient to medical attention. Neurological findings, which show considerable variations, may not be evident within the first 3 years of life. Developmental retardation, particularly of motor and speech functions is mostly noted during infancy. Additional clinical abnor-

Correspondence: Dr rer. nat. Cornelia Kraus, Institut für Humangenetik der Universität, Schwabachanlage 10, D-91054 Erlangen, Germany. Tel: +49 913185 26587; Fax: +499131 209297;

E-mail: cokraus@humgenet.uni-erlangen.de

Received 19 February 1999; revised 26 November 1999; accepted

29 November 1999 malities are seizures, glistening dots in the macular region of the retina, and short stature.

Although patients with these symptoms have been described previously, the clinical entity was delineated only in 1957 by Sjögren and Larsson. ${ }^{1}$ Up to 1994 more than 200 patients had been reported from at least 23 countries $^{2,4}$ but mostly from Sweden.

Cultured fibroblasts of patients with SLS were shown to have deficient activity of fatty aldehyde dehydrogenase $(\mathrm{FALDH}),{ }^{5}$ an enzyme that is necessary for the oxidation of fatty alcohol to fatty acid as a component of the fatty alcohol: $\mathrm{NAD}^{+}$oxidoreductase (FAO) enzyme complex. ${ }^{6}$ Therefore, affected patients with impaired fatty alcohol oxidation accumulate long-chain fatty alcohol in their tissues. ${ }^{3,6}$ Although the pathogenesis of single abnormalities is yet unclear, fatty alcohol storage is thought to be responsible for the symptoms of the disease. ${ }^{3}$ Prior to the 
identification of the SLS gene, enzymatic activity testing was necessary for diagnosis of SLS patients, carrier detection ${ }^{7}$ and prenatal diagnosis. ${ }^{8}$

The SLS gene was assigned to chromosome17p11.2 by linkage analysis $\mathrm{s}^{9,10}$ and the FALDH gene was mapped to the same locus using yeast artificial chromosomes. ${ }^{11}$ The gene consists of 10 exons spanning about $30.5 \mathrm{~kb}^{12,13}$ and the coding region encompasses $1458 \mathrm{bp}$.

After identification of the first disease-causing mutations, suitable molecular screening methods were applied. Because most of the known mutations result in a premature translational stop codon, ${ }^{11,14-18}$ we decided to use RT-PCR and a coupled in vitro transcription-translation assay as screening method. This paper will report on our findings in nine German families with Sjögren-Larsson syndrome.

\section{Material and methods \\ Patients}

The diagnosis of SLS in nine patients from Germany was concluded from the presence, though variable, of the three main symptoms, namely ichthyosis, spastic di- or tetraplegia and mental retardation. All but one have glistening macular dots. Two patients were sibs with minor findings in the male and severe abnormalities in the female. In contrast to her younger brother, the spastic tetraplegia and the mental retardation of the sister was more developed.

\section{Preparation of DNA and RNA samples}

Mutation analyses in the FALDH gene were carried out in nine unrelated SLS index patients and their parents, using genomic DNA and total RNA. Genomic DNA was extracted from $10 \mathrm{ml}$ peripheral blood by the salting-out procedure. Total RNA was isolated from $10 \mathrm{ml}$ EDTA-treated peripheral blood or from 2-3 $\times 10^{7}$ Epstein-Barr virus immortalized B-lymphocytes using the commercial $\mathrm{Tri}^{\mathrm{TM}}$ reagent kit (Sigma, Deisenhofen, Germany).

\section{Reverse transcription polymerase chain reaction}

In order to analyse the whole FALDH coding region $2 \mu \mathrm{g}$ of total RNA was reversely transcribed using the Superscript II RT (BRL, Eggenstein, Germany) according to the manufacturer's instructions.

PCR amplification of the whole FALDH coding region was carried out using the T7 promotor sequence-modified sense primer FALDHT7 5'GGATCCTAATACGACTCACTATAGGAACAGACCACCATGGAGCTCGAAGTCCGGCGG3' in combination with the antisense oligonucleotide FALDH1487 5'AGGCACTAGGAGGTTGAACAGG3'. Primer sequences were designed using the GenBank file L47162 deposited by De Laurenzi et $\mathrm{al}^{11}$

We amplified $1 \mu$ l of the cDNA in a $25 \mu$ l total reaction volume using the Expand ${ }^{\mathrm{TM}}$ Long Template PCR System (puffer system 3) according to the manufacturer's instruc- tions (Boehringer Mannheim GmbH, Mannheim, Germany).

PCR conditions were $94^{\circ} \mathrm{C}$ for $2 \mathrm{~min}$, followed by 15 cycles at $94^{\circ} \mathrm{C}$ for $10 \mathrm{~s}, 66^{\circ} \mathrm{C}$ for $30 \mathrm{~s}, 68^{\circ} \mathrm{C}$ for $2 \mathrm{~min}, 25 \mathrm{cycles}$ at $94^{\circ} \mathrm{C}$ for $10 \mathrm{~s}, 65^{\circ} \mathrm{C}$ for $30 \mathrm{~s}, 68^{\circ} \mathrm{C}$ for $2 \mathrm{~min}$ and or $20 \mathrm{~s}$ extension, and final extension at $68^{\circ} \mathrm{C}$ for $7 \mathrm{~min}$.

\section{Protein truncation test (PTT)}

Screening for translational stop mutations in the coding region of the FALDH gene was carried out by the protein truncation test (PTT). ${ }^{19}$ Approximately, 100 ng of PCR amplified products of reversely transcribed mRNA was directly used in a $12.5 \mu \mathrm{l}$ volume coupled TNT T7 reticulocyte system in vitro transcription/translation reaction (Promega, Heidelberg, Germany) substituted with in vitro translation grade $\left({ }^{35} \mathrm{~S}\right)$-L-methionine (ICN, Meckenheim, Germany). The synthesized polypeptide chains were separated by a $14 \%$ SDSpolyacrylamide gel at $200 \mathrm{~V}$ for $2 \mathrm{~h}$ at $10^{\circ} \mathrm{C}$. Fluorography was carried out after treating the gel with $1 \mathrm{~m}$ sodium salicylate for $30 \mathrm{~min}$ followed by vacuum drying of the gel and exposure to an X-omat X-ray film (Kodak, Wiesbaden, Germany) for $24 \mathrm{~h}$ at $-80^{\circ} \mathrm{C}$.

\section{cDNA cloning and sequencing}

PCR amplified products were purified with Jetsorb (Genomed, Bad Oeyenhausen, Germany) and subsequently cloned in the T-vector pCR2.1 $1^{\mathrm{TM}}$ (Invitrogen, Heidelberg, Germany). Recombinants were isolated and subsequently subjected to enzymatic dideoxy-sequencing reactions using a commercial sequencing kit (Biozym, Hess. Oldendorf, Germany) and dye-modified M13 universal primers. Sequencing products were analysed with the help of a computer assisted automated LiCor-electrophoresis apparatus (MWG, Ebersberg, Germany).

\section{Genomic DNA sequence analysis}

DNA amplification of exons2, 3, 5, 6, 9 and 10 were performed in a $25 \mu \mathrm{l}$ total reaction volume containing $2.5 \mu \mathrm{l}$ of $10 \times$ buffer, $2 \mu \mathrm{l} 2.5 \mathrm{~mm}$ dNTPs $10 \mathrm{pmol}$ of each primer, $1.5 \mathrm{mM} \mathrm{MgCl}_{2}$ and $0.6 \mathrm{U}$ Taq polymerase (PAN Script, PAN Systems, Nürnberg, Germany) and subjected to 35 PCR cycles ( $30 \mathrm{~s}$ at $94^{\circ} \mathrm{C}, 30 \mathrm{~s}$ at $55-65^{\circ} \mathrm{C}, 30 \mathrm{~s}$ at $72^{\circ} \mathrm{C}$ ). Primer sequences for the amplification of FALDH exons2, 3, 6 and 10 were already published. ${ }^{18}$ For PCR amplification of genomic FALDH exons5 and 9 we used the following primer sequences:

FALDH5MS: 5'MS-TATATAGCTGTTCTGGATGTITCC3'

FALDH5MR: 5'MR-GGGGATGCTGCCTGCGAATAG3'

FALDH9MS: 5'MS-AGCTTGCATCATCTACAGTGAAGC3'

FALDH9MR: 5'MR-GCTAGAATATGCATCTGGCAGCC3'

Primer sequences were designed using the GenBank files U75286-U75296 deposited by Rogers et al. ${ }^{13}$ Each sense primer was modified at its 5 ' end by a universal M 13 sequence (MS: 5'TGTAAAACGACGGCCAGT3') and each antisense 
primer was preceded at the $5^{\prime}$ end by a universal $M 13$ reverse sequence (MR: 5'CAGGAAACAGCTATGACC3') allowing sequence analysis as described above.

\section{Multiplex-PCR}

DNA amplification encompassing the genomic regions of exons 8 to 10 and exons 9 to 10 , respectively, was performed in one single reaction containing two different $5^{\prime}$ primers (FALDH8MS: 5'MS-TCACTGACCTGGACACCTTTGG3'; FALDH9MS: $\quad$ 5'MS-AGCTTGCATCATCTACAGTGAAGC3') and one common 3' primer (FALDH1487: 5'AGGCACTAGGAGGTTGAACAGG3'). 500 ng of genomic DNA was amplified in a $25 \mu$ l total reaction volume using the Expand ${ }^{\mathrm{TM}}$ Long Template PCR System (Boehringer Mannheim GmbH).

PCR conditions were $94^{\circ} \mathrm{C}$ for $2 \mathrm{~min}$, followed by 15 cycles at $94^{\circ} \mathrm{C}$ for $10 \mathrm{~s}, 65^{\circ} \mathrm{C}$ for $30 \mathrm{~s}, 68^{\circ} \mathrm{C}$ for $3 \mathrm{~min}, 25 \mathrm{cycles}$ at $94^{\circ} \mathrm{C}$ for $10 \mathrm{~s}, 63^{\circ} \mathrm{C}$ for $30 \mathrm{~s}, 68^{\circ} \mathrm{C}$ for $3 \mathrm{~min}$ and 20 s extension, and final extension at $68^{\circ} \mathrm{C}$ for $7 \mathrm{~min}$.

\section{Puromycin treatment}

For inhibition of nonsense mediated RNA decay lymphoblastoid cells were grown for $12 \mathrm{~h}$ in the presence of $200 \mu \mathrm{g} / \mathrm{ml}$ puromycin (Sigma, Deisenhofen, Germany) and then harvested in PBS buffer.

\section{Results}

\section{Three different exon deletions identified by RT-PCR analyses}

For initial RT-PCR analysis leukocytes from our patients and their healthy parents were collected to extract total RNA, which was reversely transcribed into complementary DNA with the help of random primers. RT-PCR based amplification of the $1458 \mathrm{bp}$ FALDH coding region was carried out and PCR products were analysed in a $1.2 \%$ agarose gel. Figure 1 depicts the results of the RT-PCR analysis in five of our nine Sjögren-Larsson families.

Using this method we were able to identify truncated RT-PCR products of reduced size in the index patients $P 1, P 2$, P3, P4 and P5 (Figure 1: Lanes 1, 6, 8, 10). Since in all four cases no full length FALDH product was observed, we speculated that they could be homozygous for the particular deletion.

RT-PCR analysis of the FALDH gene of the parents revealed that both parents of patients $\mathrm{P} 2, \mathrm{P} 3$ and $\mathrm{P} 4$ were heterozygous for the deletions (Figure 1: lanes4, 5, 7, 9). However, only one parent of patientP1 showed a shortened RT-PCR product (Figure1: lane3), whereas in the second parent (Figure1: lane2) only a FALDH-transcript of normal size was identified. Blood samples of parents of patient P5 were not available.

To characterise the missing sequences in FALDH transcripts of reduced size, aberrant cDNA products of the five patients shown in Figure 1 were cloned into the T-vector pCR2.1. Results of the sequence analysis of cloned fragments are summarised in Figure2. Sequence data derived from patients P1, P2 and P3 revealed that the RT-PCR fragments of



P1

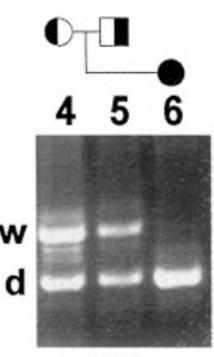

P2/P3

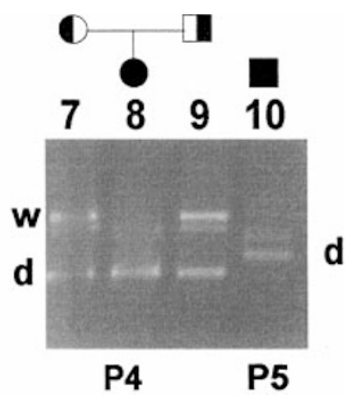

P4
Figure 1 Three different exon deletions identified by RT-PCR analyses. RT-PCR analysis of the FALDH gene of four SLS patients and their healthy parents. RT-PCR based amplification of the $1458 \mathrm{bp}$ FALDH coding region was carried out and PCR products were analysed in a $1.2 \%$ agarose gel. Full length FALDH PCR products of $1458 \mathrm{bp}(\mathrm{w})$ and RT PCR products of reduced size (d) were indicated. RT-PCR products loaded from left to right are derived from: Lane 1: SLS patient P1; Lane2: father of SLS patient P1; Lane 3: mother of SLS patient P1; Lane 4: mother of SLS patient P2/P3; Lane 5: father of SLS patient P2/P3; Lane6: SLS patient P2/P3. Lane 7: mother of SLS patient P4; Lane 8: SLS patient P4; Lane 9: father of SLS patient P4; Lane 10: SLS patient P5. Parents of P5 were not available.



Figure 2 Identification of three different FALDH exon deletions by CDNA sequencing. RT-PCR products of reduced size of patients P1, P2/P3, P4 and P5 were cloned into the T-vector PCR2.1 and individual alleles were subsequently sequenced. An aberrant 8 to 10 connection in patient $P 1$ and P2/P3 (del exon 9), an exon 1 to 4 connection in patient P4 (del exon 2/3) and an exon 1 to 3 connection in patient P5 (del exon 2) was observed. Nucleotide sequences surrounding the aberrant exon connections including deduced amino acids (one letter code) are given on the right hand side. 
reduced size were the result of exon 9 skipping (Figure2: del exon 9), which leads to an out-of-frame reading of exon 10. The probands with this deletion also have a polymorphic nucleotide exchange $1446 \mathrm{~A}>\mathrm{T}$ in exon 10 on the same allele. The combination of both mutation and polymorphism creates a premature stop codon after three altered amino acids in the last exon. Since PCR amplification with primers specific for genomic sequences of exon 9 failed to yield a product in patients $\mathrm{P} 2$ and $\mathrm{P} 3$, respectively, we postulated that exon 9 skipping detected at the RNA level could be due to a genomic deletion including exon 9, which has also been described by Sillen et al. ${ }^{18}$ This genomic deletion was further analysed in more detail (see below).

Sequence analysis of recombinant clones derived from patient P4 (Figure1: lane6) revealed that the shortened transcript was due to in-frame skipping of exon 2 and 3 (Figure2: del exon 2/3). Interestingly, this deletion resulted from two different splice donor mutations affecting exon 3. The maternal allele carried a G-deletion of the canonical GT-splice donor dinucleotide, whereas the GT-splice donor sequence of exon 3 of the paternal allele was altered by a $G$ to $\mathrm{C}$ transversion resulting in an abnormal CT site (data not shown).

The shortened transcript identified in the fifth patient P5 (Figure1: lane10) was due to exon 2 skipping creating a premature stop codon after three altered amino acids in the third exon (Figure2: del exon 2). Sequence analysis of genomic DNA of patient P5 revealed that the patient was heterozygous for an exon 2 splice donor mutation. The GT-splice donor sequence of exon 2 of one allele was altered by a $\mathrm{T}$ to $\mathrm{C}$ transition resulting in an abnormal GC site (data not shown).

\section{Characterising a genomic exon 9 deletion by multiplex-PCR analysis}

To further characterise the presumed genomic deletion of exon 9 described above, a multiplex PCR was established as shown in Figure3. Two different 5' primers specific for exon 8 and exon 9, respectively, were combined with an antisense primer located in exon 10. We theoretically expected amplification of a $4 \mathrm{~kb}$ and a $11 \mathrm{~kb}$ fragment in healthy controls, but only the smaller fragment of $4 \mathrm{~kb}$ was amplified (Figure3: lane4 and 8). With this set of primers we obtained an additional fragment of $4.4 \mathrm{~kb}$ in patientsP1, P2 and P3 (Figure 3: lanes 1 and 7 ) and in their healthy parents (Figure3: lanes $3,5,6)$. We concluded that this $4.4 \mathrm{~kb}$ fragment represents the mutated allele resulting from a $6 \mathrm{~kb}$ genomic deletion including exon 9.

This genomic analysis provided the additional information in patientP1 (Figure3, lane1) that he is heterozygous for the exon 9 deletion in contrast to the initial results obtained by RT-PCR analysis (Figure 1, lane1), which suggested expression of a single truncated FALDH transcript.

In order to map precisely the deletion breakpoints, the $4.4 \mathrm{~kb}$ junction fragments of patients $\mathrm{P} 1, \mathrm{P} 2$ and $\mathrm{P} 3$, respec-

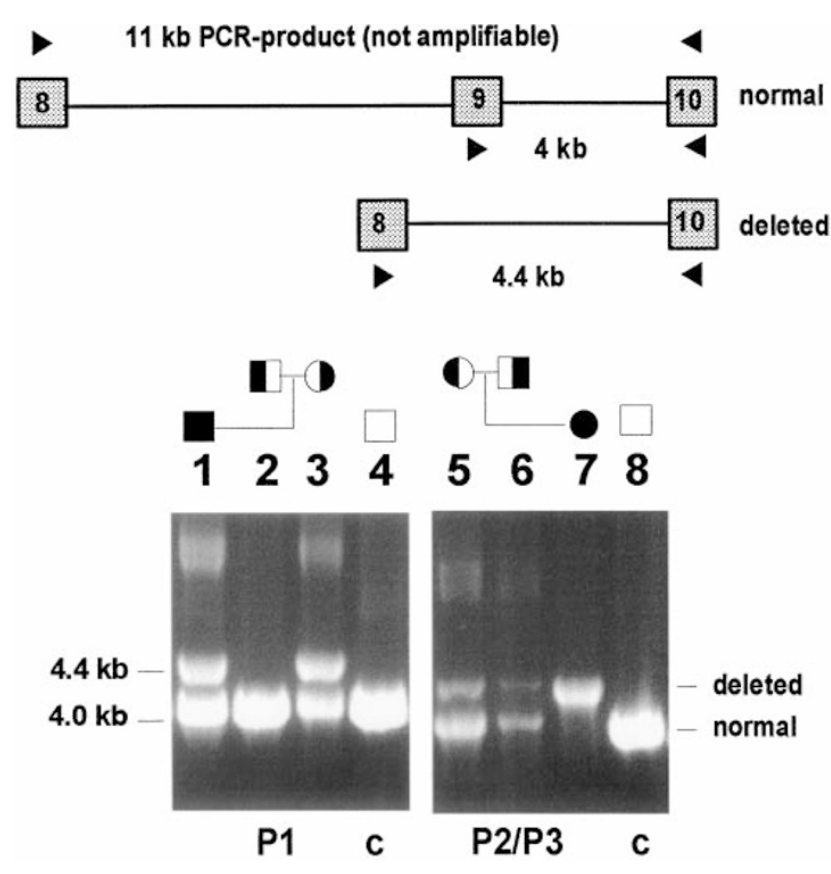

Figure 3 Multiplex PCR analysis of a genomic FALDH exon 9 deletion. DNA amplification encompassing the genomic regions of exons 8 to 10 and exons 9 to 10 , respectively, was performed in one single reaction containing two different $5^{\prime}$ primers specific for exon 8 and 9, and one 3 ' primer specific for exon 10. Expected sizes of PCR products are given in the upper scheme. The lower part documents the results of multiplex analyses of this particular genomic region in families of index patientsP1 (Lanes 1-3) and P2/P3 (Lanes5-7). PCR products loaded from left to right are derived from: Lane 1: SLS patient P1; Lane2: father of SLS patient P1; Lane 3: mother of SLS patient P1; Lane 4: healthy control; Lane 5: mother of SLS patient P2; Lane 6: father of SLS patient P2; Lane 7: SLS patientP2; Lane8: healthy control.

tively, and corresponding wild type fragments were cloned and sequenced. The forward primer to characterise the $5^{\prime}$ breakpoint of the region spanning the deletion was 5' GAT ACC CTG TGG CAT CAT TGA C $3^{\prime}$ located in intron 8 (IVS8 + 1259 to 1280). The reverse primer 5' GTT CAT CTC TGC TTA CTG GAC C 3 ' located in the alternative spliced exon $9^{*^{13}}$ was used to delineate the $3^{\prime}$ breakpoint. This led to the identification of the putative $5^{\prime}$ and $3^{\prime}$ breakpoints of the deletion as delineated in Figure4. Comparison of the junction fragment with the corresponding wild type sequence revealed 8 bp (5' AGGAGAAT 3') at the deletion junction that was identical with two $8 \mathrm{bp}$ sequences in intron 8 (IVS8 + 1644 to 1651) and intron 9 (197-204 bp downstream of exon $9 *$ ), respectively.

Therefore, we postulate that the $5^{\prime}$ breakpoint is located in between base pairs 1644-1651 upstream of exon 8 in intron 8 and the $3^{\prime}$ breakpoint is located in between base pairs 197-204 downstream of the alternative spliced exon $9 *$ in intron 9. This deletion removes about $6 \mathrm{~kb}$ and causes complete loss of exon 9. The presence of identical $8 \mathrm{bp}$ 


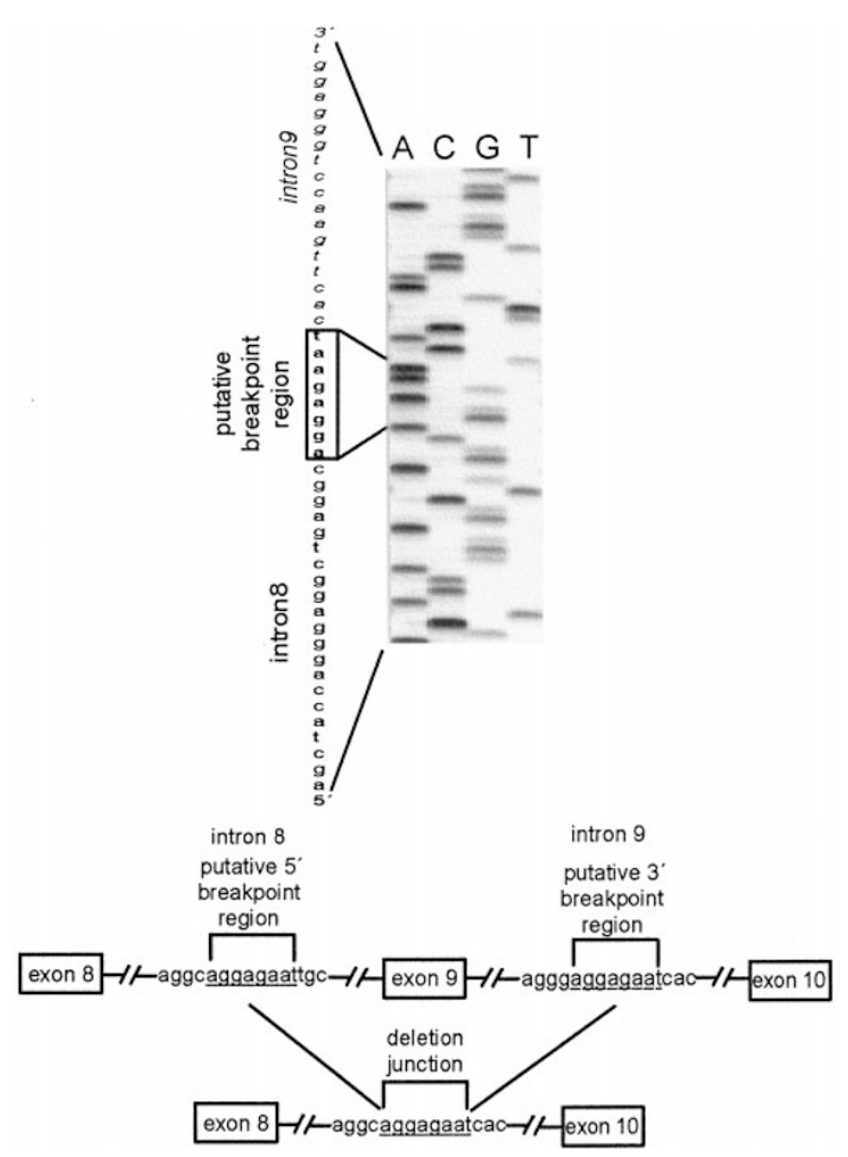

Figure 4 Characterisation of the genomic breakpoint. Upper part: Sequence data of the deletion junction and portions of the joining introns derived from the $4.4 \mathrm{~kb}$ junction fragment. Sequences 5 ' to the breakpoint region were derived from intron 8 and that in $3^{\prime}$ to the junction from intron 9 . Lower part: Nucleotide sequences from the $4.4 \mathrm{~kb}$ junction fragment and the normal fragments from intron 8 and intron 9 containing the $5^{\prime}$ and $3^{\prime}$ breakpoint regions. An $8 \mathrm{bp}$ region of homology at the deletion junction and in the vicinity of breakpoints is underlined. The putative breakpoint regions are indicated by brackets.

(AGGAGAAT) sequences at both breakpoints, with one being part of the deleted sequence, suggests a common slippage mispairing mechanism for this deletion. ${ }^{20}$

\section{Premature termination codons induce nonsense-mediated RNA decay}

Since only one allele of patient P1 appeared to be affected by the genomic $6 \mathrm{~kb}$ deletion including exon 9 (Figure 3 : lane 1 ), we considered a second mutation which could probably lead to RNA instability. Meanwhile, this particular patient had already been analysed in Sweden and was found to carry a deletion of one out of four thymidins at nucleotide position 903-906 in exon 6, designated nt906delT in addition to the genomic exon 9 deletion. ${ }^{18}$ This deletion nt906delT created a frameshift that introduced a stop signal 12 codons downstream from Ala301.

To demonstrate that this particular mutation leads to RNA instability due to a process designated 'nonsense-mediated mRNA decay', lymphoblastoid cells were treated with the translation inhibitor puromycin ${ }^{21}$ and total RNA was isolated. Upon cDNA synthesis RT-PCR analyses were carried out as shown in Figure5. In contrast to the initial RT-PCR analysis (Figure1), a full-length and a shortened FALDHtranscript were identified in patientsP1 and P5 (Figure5, lanes 2 and 8 ). In addition, a FALDH transcript of normal size was demonstrated for the first time in patientsP6 and P7 (Figure5, lanes5 and 6).

Subsequently, RT-PCR products were subjected to a coupled in vitro transcription/translation reaction and S35methionine labelled proteins were size-fractionated by polyacrylamide gel electrophoresis. ${ }^{19}$ Autoradiographic signals were obtained, which are depicted in Figure6. As expected, patientP1 (Figure6: lane2) presented a truncated polypeptide chain of $45 \mathrm{kD}$ resulting from the exon 9 deletion and an additional small polypeptide chain of $32 \mathrm{kD}$ due to the frameshift mutation in exon 6. Since the father of P1 (Figure6; lane1) is heterozygous for the latter mutation, an identical $32 \mathrm{kD}$ polypeptide chain and a $54 \mathrm{kD}$ polypeptide chain corresponding to the wild type FALDH were observed. This PTT also allowed the identification of identical truncated FALDH proteins in patients P6 and P7 (Figure6; lanes 5 and 6), respectively. Since the pattern of their in vitro translated polypeptides was similar to the low molecular

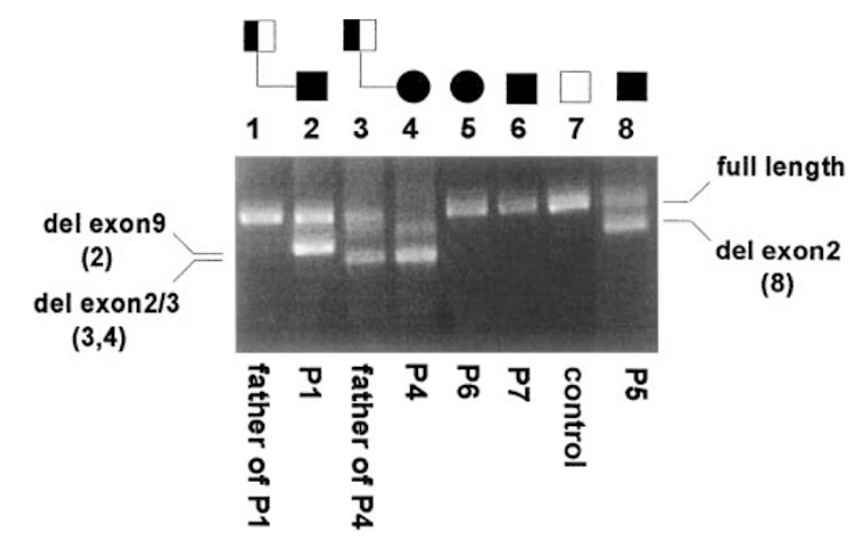

Figure 5 RT-PCR analysis of the FALDH gene after puromycin treatment. RT-PCR analysis of the FALDH gene of five SLS patients, healthy parents and one normal control person. RT-PCR based amplification of the $1458 \mathrm{bp}$ FALDH coding region was carried out on whole RNA derived lymphoblastoid cell lines after puromycin treatment. RT-PCR products were separated through a $1.2 \%$ agarose gel. The deletions identified are indicated on the margins with an assignment to the sample lanes given in brackets. RT-PCR products loaded from left to right are derived from: Lane 1: father of SLS patient P1; Lane 2: SLS patient P1; Lane3: father of SLS patient P4; Lane 4: SLS patient P4; Lanes5-6: SLS patientsP6 and P7; Lane7: normal control; Lane8: SLS patient P5. 


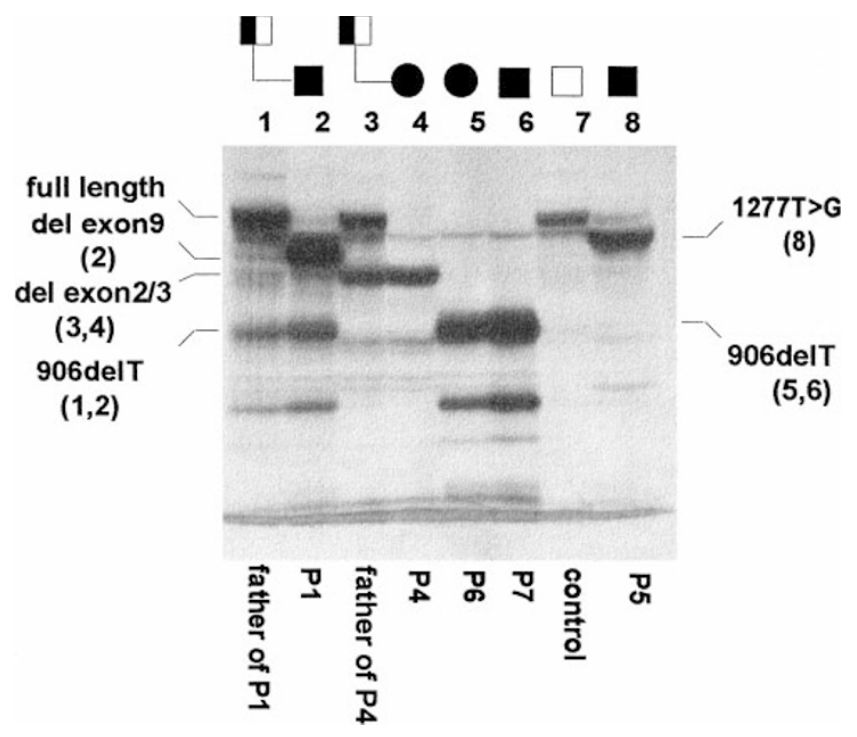

Figure 6 Protein truncation test after puromycin treatment. Reverse transcriptase-polymerase chain reaction based protein truncation test of the whole coding region of the FALDH gene. Autoradiographic signals of $\left({ }^{35} \mathrm{~S}\right)$ - L-methionine labeled in vitro synthesised proteins, that were separated through a $14 \%$ SDS-polyacrylamide gel are shown after $24 \mathrm{~h}$ of exposure to an $x$-ray film. The mutations identified in patients are indicated on the margins. The numbers in brackets given below the mutations refer to the lanes loaded. Protein samples are derived from: Lane1: father of SLS patient P1; Lane2: SLS patient P1; Lane3: father of SLS patient P4; Lane 4: SLS patient P4; Lane5: SLS patient P6; Lane6: SLS patient P7; Lane 7: control; Lane8: SLS patient.

weight bands of patient P1 and his father (Figure6, lanes 1 and 2), we expected the same 906delT alteration, which was confirmed by cDNA sequencing. Genomic sequencing of patientsP6 and P7 and their parents showed that both patients were homozygous for this particular mutation (data not shown). Interestingly, cDNA sequencing revealed that this 906delT mutation was always associated with two polymorphism 733G >A (exon 5) and 901G >C (exon 6) already described. ${ }^{18}$ These two polymorphisms were neither identified in other SLS patients nor in healthy controls (data not shown). In patient P5 a $47 \mathrm{kD}$ polypeptide chain was identified by PTT (Figure6, lane8). Cloning and sequencing of the full length RT-PCR product of P5 revealed a TTA $\rightarrow$ TGA transversion at nucleotide position 1277 , which resulted in an Leu426Ter stop mutation in exon 9. In this patient the exon 2 skipping initially shown by RT-PCR resulted in a $4.9 \mathrm{kD}$ polypeptide chain. This latter fragment was not identifiable by the PTT.

With the help of the PTT and subsequent CDNA sequencing in patientP8 the identical 906delT mutation as in patientsP1, P6 and P7 was identified on one FALDH allele. On the second FALDH allele a deletion of GA at nucleotide position 1297-1298 in exon 9 was identified (data not shown). This deletion in exon 9, designated 1297delGA, was already described by other groups. ${ }^{15,16,18}$ In patient P9 a wild type FALDH and a truncated polypeptide were identified by the PTT (data not shown). Cloning and sequencing of the cDNA revealed the identical 1297delGA deletion as described in patient P8 on one FALDH allele. On the other allele a TAT $\rightarrow$ AAT transversion was identified at nucleotide position 835, which resulted in a Tyr279Asn missense mutation in exon 6. Comparison of the amino acid sequence of human FALDH to rat microsomal aldehyde dehydrogenase (rmsALDH), human stomach ALDH3 (hALDH3), and human ALDH7 (hALDH7), revealed that Tyr279 is conserved in rmsALDH and hALDH3, but not in hALDH $7 .{ }^{11}$ To exclude that Tyr279Asn is a polymorphism, 35 control persons were analysed. None of them showed this alteration in exon 6. Therefore, we postulate that Tyr279Asn is a missense mutation inactivating the second FALDH allele of patient P9.

\section{Discussion}

The present paper describes our efforts to identify mutations in the FALDH gene of nine German families in which at least one child suffered from SLS. Seven of them are living in a limited region in Northern Bavaria, one in Southern Bavaria and one in Northern Germany. To our knowledge neither the parents are consanguineous nor the families are related to each other.

An initial screening revealed that the most common point mutation $\mathrm{C} 943 \mathrm{~T}^{14,17}$ was not identified in any of our analysed patients. For further screening of the FALDH gene we used RT-PCR analysis, RT-PCR based PTT, CDNA sequencing, genomic amplification and DNA sequencing. With the help of these combined methods we were able to identify eight different mutations and three different polymorphisms listed in Table1 and Table2. Both disease causing mutations were uncovered in the 9SLS families examined (Table3).

This is the first paper using RT-PCR and PTT to screen for mutations in the FALDH gene. Using this approach the molecular analysis of our patients uncovered two different types of mutational mechanisms.

First, RT-PCR analyses carried out on RNA isolated from untreated peripheral blood cells revealed different exon deletions in SLS patients and their healthy parents (Figure 1). The second type of mutation consisted of one or two base pair deletions and a single base pair exchange within different exons which resulted in premature stop codons and were identified by truncated polypeptide chains in the PTT (Figure6). In the course of our experiments we realised, that in these instances RT-PCR products were never obtained when RNA was extracted from peripheral blood cells. This observation suggested that these mutated mRNA molecules with premature stops might undergo nonsense-mediated RNA decay.

The mechanisms leading to reduced mRNA levels are unclear, as mRNA processing, transport, stability and/or translation could be involved. ${ }^{22}$ Our own data give strong 
Table 1 FALDH mutations identified in nine German SLS patients ( $n / 18$ number of FALDH chromosomes with the mutation in the sample of 18 FALDH chromosomes)

\begin{tabular}{|c|c|c|c|c|c|c|}
\hline Exon & Genomic DNA change & cDNA change & Consequence & Identified by & $\mathrm{n} / 18$ & Reference \\
\hline 2 & IVS2+2T $>C$ & del exon 2 & out of frame deletion of exon 2 ; termination & RT-PCR & $1 / 18$ & this study \\
\hline 3 & IVS3+1delG & del exons $2+3$ & in frame deletion of exons $2+3$ & RT-PCR & $1 / 18$ & this study \\
\hline 3 & IVS3+1G $>C$ & del exon $2+3$ & in frame deletion of exon $2+3$ & RT-PCR & $1 / 18$ & this study \\
\hline 6 & $835 T>A$ & $835 T>A$ & Tyr279Asn & sequencing & $1 / 18$ & this study \\
\hline 6 & 906delT & 906delT & frameshift; termination & PTT & $6 / 18$ & 18 \\
\hline 9 & $6 \mathrm{~kb}$ genomic deletion & del exon 9 & out of frame deletion of exon 9 , termination & RT-PCR & $5 / 18$ & 18 \\
\hline 9 & $1277 T>G$ & $1277 T>G$ & Leu426Ter, termination & PTT & $1 / 18$ & this study \\
\hline 9 & 1297delGA & 1297delGA & frameshift, termination & PTT & $2 / 18$ & $15,16,18$ \\
\hline
\end{tabular}

Note: numbering of the nucleotides (nt) and amino acids is in accord with the GenBank file L47162 starting with the A of the initiator ATG as nt number 1 .

Table 2 Sequence polymorphisms/variations identified in nine German SLS patients

\begin{tabular}{lllllll}
\hline Exon & Genomic DNA change & CDNA change & Consequence & Identified by & Frequence of heterozygosity & Reference \\
\hline 5 & $733 \mathrm{G}>\mathrm{A}$ & $733 \mathrm{G}>\mathrm{A}$ & Asp245Asn & sequencing & only on SLS alleles in combination with 906delT & 18 \\
6 & $901 \mathrm{G}>\mathrm{C}$ & $901 \mathrm{G}>\mathrm{C}$ & Ala301Pro & sequencing & only on SLS alleles in combination with 906delT & 18 \\
10 & $1446 \mathrm{~A}>\mathrm{T}$ & $1446 \mathrm{~A}>\mathrm{T}$ & Ala482Ala & sequencing & 0.385 & 18 \\
\hline
\end{tabular}

Note: numbering of the nucleotides ( $\mathrm{nt}$ ) and amino acids is in accord with the GenBank file L47162 starting with the A of the initiator ATG as nt number 1.

Table 3 SLS patients and identified SLS alleles

\begin{tabular}{|c|c|c|}
\hline$\overline{\text { Patient }}$ & Allele 1 & Allele 2 \\
\hline P1 & [del exon 9; 1446A>T] & [733G $>A ;$ 901G $>C ;$ 906delT] \\
\hline P2 & [del exon $9 ; 1446 \mathrm{~A}>\mathrm{T}$ ] & [del exon 9; 1446A>T] \\
\hline P3 & [del exon 9; 1446A>T] & [del exon $9 ; 1446 \mathrm{~A}>\mathrm{T}]$ \\
\hline P4 & IVS3+1delG & IVS3 $+1 \mathrm{G}>\mathrm{C}$ \\
\hline P5 & $1277 T>G$ & IVS2 $+2 T>C$ \\
\hline P6 & [733G $>A ;$; 901G $>C ;$ 906delT] & [733G $>A ;$;01G $>C ; 906 \mathrm{delT}]$ \\
\hline P7 & [733G >A; 901G >C; 906delT] & [733G >A; 901G $>C ; 906 \mathrm{delT}]$ \\
\hline P8 & 1297delGA & [733G $>A ; 901 G>C ; 906 \mathrm{delT}]$ \\
\hline P9 & 1297delGA & $835 T>A$ \\
\hline
\end{tabular}

Note: complex SLS alleles are given in brackets; numbering of the nucleotides (nt) and amino acids is in accord with the GenBank file L47162 starting with the A of the initiator ATG as nt number 1.

support to the theory that cytoplasmatic ribosomes are involved in the pathway of nonsense-mediated mRNA decay since application of the translation inhibitor puromycin increased the steady-state level of the mutated mRNA (Figure5 and Figure6).

Nonsense-mediated mRNA is a mechanism evolved by cells to get rid of aberrant transcripts and proteins. Through rapid degradation of transcripts containing premature stop codons the synthesis of incomplete and potentially deleterious proteins is prevented. However, it is unknown to what extent the remaining altered FALDH transcripts in patientsP1, P2, P3, P4 and P5 are translated in functional proteins and whether they have a dominant negative or a moderating effect.

It is noteworthy that the different mutations were not related to specific clinical manifestations of the disease. All patients were typically affected.

As the first German patients with SLS had been noted in a limited region of Northern Bavaria ${ }^{23}$ the question was rai sed whether a possible regional clustering could be due to the presence of Swedish soldiers during the 30 Years War (1618-1648) in this area with special reference to a camp near Nürnberg. ${ }^{24}$ If this hypothesis were true we would expect the same genetic alteration not only in all our patients, but the mutation should also be the same as in the Swedish patients. However, on the other hand it was shown that not all Swedish SLS patients shared the same genotype. Particularly, one of the most common Swedish mutations, $943 \mathrm{C}>\mathrm{T}$, which replaces a highly conserved proline 315 with serine was not identified in our families. The second common SLS mutation, 1297delGA, which, together with the $943 \mathrm{C}>\mathrm{T}$ mutation, is reported to account for $48 \%$ of the SLS alleles ${ }^{14}$ was, however, identified in two of our analysed families. On the other hand, the two most common mutations in the Northern Bavarian SLS patients are the chromosomal exon 9 deletion and the 906delT in exon 6 . The latter mutation is always associated with a $901 \mathrm{G}>\mathrm{C}$ polymorphism in the same exon and a 733G >A polymorphism in exon 5. Both alterations have not shown in Swedish patients. Moreover, two of the seven Northern Bavarian patients are homozygous for the exon 9 deletion. Two of them are homozygous for the exon 6 mutation and one further patient is compound heterozygous for both mutations. Therefore these two mutations together account for $71 \%$ (10/14) of the Northern Bavarian SLS alleles analysed. Interestingly, these two mutation have only been described in German SLS patients so far. However, as the exon 6 mutation is al ways associated with $901 \mathrm{Ggt}$; $C$ in exon 6 and with $733 \mathrm{G}>\mathrm{A}$ in exon 5 of the same allele, a common origin might be possible. Analyses of all SLS patients, their parents and 60 normal controls revealed that both polymorphisms are only present in patients and their parents who carry the exon 6 mutation. Thus our findings did not support the 'historical' hypothesis 
but rather suggest that two new mutations causing SLS syndrome originated in Northern Bavaria.

\section{Acknowledgements}

The expert technical assistance of M rs A Vogler, Mrs B Schenker and Mrs K Thoma is gratefully acknowledged. The authors thank $\operatorname{Dr} D$ Abeck, Dr KH Grimm, Dr M Greiwe and Dr L Neumann for referring SLS patients included in this study.

\section{References}

1 Sjögren T, Larsson T: Oligophrenia in combination with congenital ichthyosis and spastic disorders. Acta Psychiatr Neuro Scand 1957; 32: 1-113.

2 Jagell $\mathrm{S}$, Gustavson $\mathrm{KH}$, Holmgren $\mathrm{G}$ : Sjögren-Larsson syndrome in Sweden. A clinical, genetic and epidemiological study. Clin Genet 1981; 19: 233-256.

3 Rizzo WB: Sjögren-Larsson syndrome. Sem Dermat 1993; 12: 210-218.

4 Theile U: Sjögren-Larsson syndrome: oligophrenia-ichthyosisdi/tetraplegia. Humangenetik 1974; 22: 91-118.

5 Rizzo WB, Craft DA: Sjögren-Larsson syndrome: Deficient activity of the fatty aldehyde dehydrogenase component of fatty alcohol: $\mathrm{NAD}^{+}$oxidoreductase in cultured fibroblasts. J Clin Invest 1991; 88: $1643-1648$

6 Rizzo WB, Dammann AL, Craft DA et al: Sjögren-Larsson syndrome: Inherited defect in the fatty alcohol cycle. J Pediatr 1989; 115: 228-234.

7 Kelson TL, Craft DA, Rizzo WB: Carrier detection for SjögrenLarsson syndrome. J Inherit M etab Dis 1992; 15: 105-111.

8 Rizzo WB, Craft DA, Kel son TL et al: Prenatal diagnosis of SjögrenLarsson syndrome using enzymatic methods. Prenat Diagn 1994; 14: $577-581$.

9 Pigg M, Jagell S, Sillen A, Weissenbach J, Gustavson KH, Wadelius C: The Sjögren-Larsson syndrome gene is close to D17S805 as determined by linkage analysis and allelic association. Nat Genet 1994; 8: 361-364.

10 Rogers GR, Markova NG, De Laurenzi V, Rizzo WB, Compton JG: Genetic homogeneity in Sjögren-Larsson syndrome: Linkage to chromosome17p in families of different non-Swedish ethnic origin. Am J Hum Genet 1995; 57: 1123-1129.

11 De Laurenzi V, Rogers GR, Hamrock DJ et al: Sjögren-Larsson syndrome is caused by mutations in the fatty aldehyde dehydrogenase gene. Nat Genet 1996; 12: 52-57.
12 Chang C, Yoshida A: Human fatty aldehyde dehydrogenase gene (ALDH10): Organisation and tissue-dependent expression. Genomics 1997; 40: 80-85.

13 Rogers GR, Markova NG, De Laurenzi V, Rizzo WB, Compton JG: Genomic organization and expression of the human fatty aldehyde dehydrogenase gene (FALDH). Genomics 1997; 39: 127-135.

14 De Laurenzi V, Rogers GR, Tarcsa E et al: Sjögren-Larsson syndrome is caused by a common mutation in Northern European and Swedish patients. J Inv Derm 1997; 109: 79-83.

15 Rizzo WB, Carney G, De Laurenzi V: A common deletion mutation in European patients with Sjögren-Larsson syndrome. Biochem Molec Med 1997; 62: 178-181.

16 Tsukamoto N, Chang C, Yoshida A: Mutations associated with Sjögren-Larsson syndrome. Ann Hum Genet 1997; 61: 235-242.

17 Sillen A, Jagell S, Wadelius C: A missense mutation in the FALDH gene identified in Sjögren-Larsson syndrome patients originating from the northern part of Sweden. Hum Genet 1997; 100: 201-203.

18 Sillen A, Anton-Lambrecht I, Braun-Quentin C et al: Spectrum of mutations and sequence variants in the FALDH gene in patients with Sjögren-Larsson syndrome. Hum Mut 1998; 12: 377-384.

19 Kraus C, Günther K, Vogler A, Hohenberger W, Pfeiffer RA, Ballhausen WG: Rapid RT-PCR based protein truncation test in the screening for $5^{\prime}$ located mutations of the APC gene. Mol Cell Probes 1998; 12: 143-147.

20 Cooper DN, Krawczak M: Human Gene Mutation. Bios Scientific: Eynsham, UK, 1993.

21 Andreutti-Zaugg C, Scott RJ, Iggo R: Inhibition of nonsensemediated messenger RNA decay in clinical samples facilitates detection of human MSH2 mutations with an in vivo fusion protein assay and conventional techniques. Cancer Res 1997; 57: 3288-3293.

22 Maquat LE: When cells stop making sense: Effect of nonsense codons on RNA metabolism in vertebrate cells. RNA 1995; 1: 453-465.

23 Jäger B: Das Sjögren-Larsson Syndrom - ein Bericht über fünf Patienten aus dem nordbayerischen Raum. Dissertation. Institut für Humangenetik: Erlangen.

24 Braun-Quentin C, Bathke KD, Pfeiffer RA: Das Sjögren-Larsson Syndrom in Deutschland. Deutsches Ärzteblatt 1996; 93: 1039-1043. 